\title{
Desarrollo emocional y creativo en Educación Infantil mediante las artes visuales y la música
}

\section{Emotional and creative development in early childhood education though the visual arts and music}

Ana María Botella Nicolás ${ }^{1}$

Amparo Fosati Parreño

Regina Canet Benavent

\section{Resumen}

En esta investigación se pretende demostrar que utilizando los lenguajes de las artes y la música de una manera óptima, se obtienen beneficios que contribuyen a la formación integral del alumnado. A través de éstos se puede trabajar de una manera transdisciplinar y significativa la emoción y la creatividad por estar vinculadas a la Educación Infantil, una etapa educativa en la que el alumnado se rige mediante el hemisferio derecho del cerebro. Los resultados apuntan que las artes visuales y la música son necesarias para proporcionar un desarrollo integral del alumnado $\mathrm{y}$, de manera transdisciplinar permiten trabajar todo tipo de conocimientos y sentimientos que pueden alfabetizar en todos los ámbitos posibles.

Palabras clave: artes, música, emoción, creatividad, Educación Infantil.

\section{Abstract}

This research pretends to show that, using arts and musical languages in an optimal way, benefits, which contribute to develop integral training, are obtained. Through these languages it is possible to work on emotions and creativity, by a transdisciplinary and meaningful method, because they are linked to the Early Childhood Education: an educational stage when students mainly use the right hemisphere of the brain. The results indicate that the visual arts and music are necessary to provide an integral development of the students and, in a transdisciplinary way, allow the work in all kinds of knowledge and feelings that can be literate in all possible areas.

Keywords: arts, music, emotions, creativity, Early Childhood Education.

\footnotetext{
1 Departamento de Didáctica de la Expresión Musical, Plástica y Corporal de la Facultad de Magisterio de la Universitat de València. Ana.Maria.Botella@uv.es; Amparo.Fosati@uv.es; recabel@alumni.uv.es Artículo recibido: 23 de marzo de 2017; aceptado: 30 de abril de 2017.
} 


\section{Introducción}

Este artículo pretende ser una aportación significativa a favor de trabajar las artes visuales y la música de manera transdisciplinar en la etapa de Educación Infantil, teniendo en consideración las emociones y la creatividad. Actualmente hay muy poco investigado y escrito en este campo porque la inteligencia emocional en la educación es algo novedoso que empieza a tomar relevancia desde hace escaso tiempo.

Desde la entrada en vigor de la LOGSE, la Educación Infantil es considerada una etapa educativa con carácter y currículum propio ${ }^{2}$. Dentro de éste, se destaca la necesidad de trabajar las artes en las tres áreas de conocimiento en las que está estructurado. Este artículo trata de mostrar que se puede ir más allá de la visión de artes como materias aisladas e inconexas con el resto de actividades. Pueden ayudar al docente a trabajar más conceptos y facilitar el desarrollo del hemisferio derecho del cerebro. Aunque la música y las artes visuales son lenguajes diferentes, se completan, y el saber utilizar una metodología en la que el alumnado sea el protagonista de su aprendizaje, proporciona un desarrollo integral de su personalidad.

En el marco legal en el cual se constituye la Educación Infantil, se observa la importancia otorgada a las artes. Este hecho transciende de manera poco general en las aulas, porque existe todavía una tendencia a pensar que son trabajos manuales, reducidos a la producción de un producto final siguiendo unos pasos concretos. En el caso de la música también se le otorga un lugar reducido sin aprovechar todas aquellas posibilidades que puede ofrecer. De manera que, estando en el siglo XXI todavía está presente el carácter propedéutico que se le otorgaba a la Educación Infantil. Este hecho se observa con la preocupación, tanto por docentes como por las familias, porque sus hijos aprendan a leer y escribir cuanto antes, utilizando para ello metodologías más tradicionales que focalizan su interés en unas determinadas inteligencias.

Cuando el alumnado entra en contacto con actividades artísticas, está desarrollando habilidades que tendrán grandes beneficios a largo plazo. El arte genera emociones y activa agentes neurotransmisores como la serotonina, adrenalina y dopamina que modifican la sinapsis neuronal que es el proceso básico para el aprendizaje.

Como justifica Swanwick [2000, p. 54], "las artes como modos de conocimiento pueden ser tan eficientes como cualquier otra vía de discurso humano, y son igualmente capaces de contribuir al desarrollo de la mente a nivel conceptual".

El alumnado de Educación Infantil requiere tener propuestas educativas que le permitan desarrollar tanto su imaginación y su forma de expresarse como sus capacidades motoras y cognitivas. Se trata de plantear actividades que no sean cerradas, pasivas, o monótonas y que contengan un componente emotivo que deje espacio a la creatividad.

\footnotetext{
${ }^{2}$ El Decreto 38/2008 del 28 de marzo del 2008, vigente actualmente, establece el currículum del segundo ciclo de la Educación Infantil de la Comunidad Valenciana.
} 


\section{Objetivos}

El objetivo general de esta investigación fue realizar un estudio de la metodología de los docentes de Educación Infantil del CEIP Doctor Esplugues de Montaverner.

Observar cómo trabajan la educación artística y la música, destacando la importancia de la creatividad y la inteligencia emocional. Dentro de este objetivo, establecimos los siguientes secundarios:

- Comprobar si es la metodología el factor más relevante en la formación del alumnado.

- Conocer la importancia que se le otorga a la música y al arte en Educación Infantil en este centro.

- Identificar la repercusión de las emociones en el aprendizaje.

- Contribuir de la música y el arte en las emociones y creatividad del alumnado.

- Nombrar algunas ventajas o inconvenientes actuales que facilitan/dificultan trabajar las artes y la música y por ende, emoción y creatividad.

\section{Fundamentación}

Los conocimientos nombrados han ido evolucionando hasta concretar y aceptar que el ser humano no posee un sólo tipo de inteligencia, sino varias. Gardner [1994, p. 11] lo expresa del siguiente modo "los seres humanos han evolucionado para mostrar distintas inteligencias y no para recurrir de diversas maneras a una sola inteligencia flexible". Han ido evolucionando hasta concretar y aceptar que el ser humano no posee un sólo tipo de inteligencia, sino varias.

Aunque actualmente las inteligencias de Gardner son ocho, nos centraremos en cuatro: la inteligencia intrapersonal, la interpersonal, la musical y la visual-espacial. Es obvio que el trabajar las emociones y la creatividad va a implicar una pluralidad de inteligencias que van a estar presentes, en este estudio nos centraremos en las nombradas anteriormente. Con esta teoría, se abre una nueva perspectiva que afecta de manera positiva a la labor docente y a la potencialidad del alumnado, pudiendo conseguir a través de esta nueva concepción, incrementar y motivar en el alumnado sus cualidades, beneficiando a la etapa educativa de 3 a 6 años en la que los sentidos son la forma primaria que poseemos para tener conciencia con el medio.

Bisquerra [2013, p. 45] destaca que "las emociones positivas producen una predisposición a la aproximación, mientras que las emociones negativas a la evitación”. El alumnado tenderá a realizar aquellas tareas que le resultan agradables, positivas y significativas y rechazará aquellas que no le proporcionen sensaciones placenteras. Por tanto, habrá que buscar actividades que activen la preferencia del alumnado hacia dicha aproximación. 


\subsection{La inteligencia de las emociones.}

En las culturas existentes hay creencias diversas, pensamientos diferentes, costumbres que al compararlas resultan incluso contradictorias con las que una persona posee. En cambio, las emociones son puntos divergentes que significan lo mismo para cada cultura, son un lenguaje universal, por este motivo, establecen una conexión a nivel tanto interior como global. Mediante las emociones se puede empatizar y conseguir que las relaciones interpersonales sean más fructíferas, evitando así futuros conflictos si se alfabetiza e inicia al alumnado de Educación Infantil en ellas. Procedemos a profundizar un poco más en este concepto, Arnheim [1993, p. 44] nos lleva a una agudización de pensamiento cuando argumenta lo siguiente:

[...] lo que se suele designar como 'una emoción' es en realidad un conglomerado de tres componentes: un acto de cognición, una lucha motivacional causada por la cognición y un despertar causado por ambas [...] toda actuación humana de cierta complejidad contiene los tres componentes.

Por tanto, podemos extraer de esta información que la emoción es un acto de inteligencia, y que es equiparable a otras tareas en las que se requiera cierto grado de complejidad, no quedando la emoción como un nivel básico de cognición. También es necesario remarcar que todo cuanto hacemos lleva implícita una emoción, desde un juego, un descubrimiento científico...de aquí la necesidad de iniciar la alfabetización del alumnado de Educación Infantil en las emociones porque estarán presentes al largo de toda su vida, siendo el aprender a ser la enseñanza en la cual se verán inmersos constantemente.

\subsection{Educación artística y sus aportaciones a la Educación Infantil.}

Es aconsejable partir de la emoción, por la selectividad que tiene este alumnado para discriminar temas que son de su interés y por sus cortos periodos de atención. De manera que es plausible una educación en la que se trabaje no sólo un tipo de inteligencia, sino que se aprovechen aquellas que más se adecuen tanto a la capacidad cognitiva, interés y motivación del alumnado. Un punto favorable que avala esta teoría es según Goleman [1996, p. 34] que "quienes apoyan una noción general de la inteligencia también destacan la flexibilidad cada vez mejor documentada del cerebro humano durante los primeros años de vida". Se ha de concebir el hecho de trabajar las inteligencias múltiples no como una metodología de trabajo, sino como la oportunidad de brindar experiencias o situaciones de aprendizaje concretas a las características y gustos de cada alumno/a. Una vez aclarada esta conceptualización, vamos a plasmar el significado de las artes, englobando en este único término artes visuales y música. Por otra parte Arnheim [1993, p. 44) argumenta que:

En esta etapa educativa el arte se va a entender como emoción y sentimiento puesto que en esta edad no sería adecuado pretender que el alumnado se inicie en el análisis de las obras de arte o técnicas 
utilizadas para determinados cuadros. En esta etapa se inicia al alumnado en el arte de manera que le ayude a expresar, crear, etc...

Con la información tratada hasta el momento aportamos que las artes pueden entenderse como la expresión de la parte más singular que posee el alumnado, la máxima expresión de la educación personalizada y adaptada a cada necesidad concreta del alumnado. Ahora es cuando surge una de las preguntas que más controversia genera entre la comunidad educativa: ¿por qué enseñar arte? Langer [citado por Eisner, 2005, p. 8] opina que:

El arte es tanto una actividad cognitiva como una actividad basada en el sentimiento, entonces el problema gira en torno a la labor de ampliar el concepto de cognición normalmente aceptado, concepto que la restringe en exceso a una mediación discursiva.

Esta respuesta aporta la necesidad de ampliar el concepto de inteligencia de manera que, en las artes se reconozcan la parte de cognición y de emoción que se trabaja mediante ellas.

En el currículum del segundo ciclo de la Educación Infantil se otorga importancia a las artes en su significado más amplio, puesto que aparece en las tres áreas en las que está estructurado. De este modo, el docente tiene un aval legal para poder diseñar la metodología que crea oportuna y que ayude a desarrollar dichas capacidades utilizando las artes, puesto que el Decreto 38/2008 les otorga cierta importancia y las considera necesarias para el desarrollo integral del alumnado.

Eisner [2004, p. 43] destaca que "las artes invitan a los niños a prestar atención a las características expresivas del entorno, a los productos de su imaginación y a trabajar un material para que exprese o suscite una respuesta emocional". En la escuela, las tareas que se diseñan potencian aspectos concretos del alumnado que pueden ayudar a definir el tipo de pensamiento que los estudiantes desarrollarán. La metodología docente, formará parte del marco de referencia que vaya construyendo el alumnado porque los conocimientos que entran en contacto con él, ayudan a crear su base cognitiva. Son el cimiento de su personalidad tanto a nivel cognitivo como emocional. Por este motivo, se considera viable establecer una metodología flexible y enriquecedora que pueda maximizar la aportación de contenidos y experiencias que se proporcionen en las escuelas. Una de las maneras de aumentar estos contenidos y conectarlos unos con otros sería mediante la utilización de una vertiente transdisciplinar.

\subsection{Algunos problemas destacables de la enseñanza artística actual.}

Uno de los primeros problemas con los que nos encontramos para que las artes tengan la misma importancia que cualquier otra materia es el hecho de considerarlas de bajo contenido cognitivo. Swanwick [2000, p. 55] argumenta que:

Las artes se consideran supraverbales: sistemas rebosantes de formas precisas ricamente articuladas 
que requieren estratos de experiencia e intuición para comprenderlas. Por el hecho de que las artes visuales, la música y danza sean esencialmente no verbales y se disfruten con aparente facilidad no debemos suponer que tengan un nivel bajo de contenido cognitivo.

Con ellas, se unen elementos imaginativos, imitativos, de creación, expresión, ejecución...de manera que el verdadero problema reside en no saber proporcionar un equilibrio verdaderamente dinámico, enriquecedor y multidisciplinar en su uso.

Según Esiner [2004, p. 129]:

El aprendizaje rara vez es significativo cuando se limita a una experiencia única, lo que se necesita son oportunidades secuenciales de trabajar en problemas con un material, tiempo para familiarizarse con él y tiempo para aprender a abordar los problemas planteados por el material para poder llegar a dominarlo.

Es cierto que la educación artística queda relegada en cierto modo a lo que conocemos por trabajos manuales. Si se utilizan las artes de este modo, no interviene ningún proceso intelectual, porque no existe un momento dedicado a los conocimientos previos que posee el alumnado en referencia al tema que se va a tratar, ni un momento de reflexión... sólo se realiza un proceso repetitivo siguiendo unos pasos de manera mecánica. Por este motivo, Eisner incide en que si algo es inconexo no se logrará sacar todo el partido pedagógico que se podría porque la pedagogía de la repetición, impera sobre la pedagogía creativa.

\subsection{Aproximación al concepto de creatividad.}

Este concepto ha ido desde una concepción divina y evolucionistas, avanzando hasta un significado interno del individuo basado en la capacidad de imaginar, la capacidad mental o la autorrealización [entre otros] hasta los significados actuales que aquí se presentan. De la Torre [2006, pp. 137-139] la define como "la creatividad es un bien social, una decisión y un reto de futuro, diferenciándose de otros conceptos psicosociales por su carácter alocéntrico, poliédrico, ético y constructivo, paradójico y problemático".

Csikszentmihalyi [1998, pp. 16-17] explica que la creatividad es como "una fuente fundamental de sentido en nuestras vidas". Este autor hace mención a las dos razones más importantes que le llevan a definirla de esta manera. La primera es que "compartimos el 98\% de nuestra carga genética con los chimpancés y nuestra diferencia entre ellos es nuestro lenguaje, los valores, expresión artística, inteligencia científica y tecnológica". La segunda razón que destaca es la plenitud que proporciona el entregarnos a ella, el vivir los momentos que proporciona.

Toro [2008, p. 3] expone por qué es necesaria la creatividad argumentando que: "La creatividad en la educación es imprescindible, no para que algunos sean genios, sino para que nadie sea esclavo". 
La creatividad no puede despegarse de la parte emocional que lleva adherida porque la parte emocional influirá en la parte creativa y en todo el aprendizaje del alumnado en general. Si existe un conflicto emocional en algún alumno, su atención va a estar focalizada en ese problema, no va a estar receptivo a los aprendizajes ni podrá conseguir centrarse en ningún tipo de tarea hasta que se dé respuesta a su preocupación. Por este motivo, creemos oportuno desarrollar el punto siguiente.

\subsection{La creatividad emocional.}

De manera breve se expone a qué hace referencia la creatividad emocional, la podríamos definir según Ruiz, [2010, p. 56] como:

\footnotetext{
La habilidad de comprender, conocer, acceder y expresar nuestras emociones y la de los demás; de resolver los problemas o conflictos personales, intrapersonales y interpersonales, de forma original, novedosa, útil y de calidad, al mismo tiempo que nos permite conocernos mejor a nosotros mismos y a los demás.
}

Retomando lo tratado al finalizar el punto anterior, hemos de tener en cuenta que las emociones alterarán la productividad creativa. De este modo, podemos iniciar al alumnado para que las emociones las vivencien también de una manera más creativa, no sólo utilizando el lenguaje oral o escrito, sino a través de otros vehículos de expresión como puedan ser diferentes tipos de arte [teatro, bailes, artes visuales,...]. Así se podrá trabajar la creatividad emocional, proporcionando un enfoque de actitud más positivo para esta edad y favorecer el proceso de mielinización de las neuronas -en el que se encuentran este alumnado- al proporcionarles experiencias placenteras y positivas.

\section{Diseño de la investigación}

\subsection{Contextualización del centro.}

Las variables socioculturales más destacables son las siguientes: se trata de una población de alrededor de 1800 habitantes, situada en una zona de habla en valenciano con poca presencia de inmigrantes. Este centro cuenta con 9 clases que abarcan desde $2^{0}$ ciclo de Educación Infantil hasta el tercer ciclo de primaria [hay una unidad por cada curso educativo]. Las aulas están distribuidas en dos pabellones, uno para educación primaria y otro de menor tamaño destinado a Educación Infantil. En éste hay una sala de usos múltiples, la sala de los docentes, un pequeño almacén y servicios para los docentes y el alumnado. Hay un patio exclusivo de Educación Infantil con una zona de juegos de arena, columpios, una cabaña de madera de unos $20 \mathrm{~m}^{2}$ y una zona vallada con pájaros. Haciendo referencia al equipamiento de exterior cuenta con: neumáticos, maderas y diferentes materiales recuperados. 
La plantilla del personal docente del centro es la siguiente: docentes en Educación Infantil: 3 tutores y 1 de refuerzo, 6 maestros de primaria, 1 especialistas de inglés, 1 especialista de educación física, 1 especialista de Pedagogía Terapéutica. También cuenta con docentes a tiempo parcial: 1 de Audición y Lenguaje y la maestra de religión. También se cuenta con un psicólogo del gabinete municipal. La relación del alumnado matriculado actualmente en el ciclo de Educación Infantil es un total de 45 alumnos.

Las clases de Educación Infantil están organizadas por zonas y rincones que proporcionan variedad de experimentación y aprendizajes. El horario de clases de Educación Infantil es flexible y orientativo y tanto las rutinas como las actividades pueden variar. Sólo existe más rigidez con las clases de los especialistas. El agrupamiento del alumnado de Educación Infantil varía en función a aquello que se pretende realizar: gran grupo, pequeño grupo, talleres, comisiones de trabajo, grupo de actividad y también mediante interniveles.

Por último, cabe mencionar que la metodología empleada por los docentes de Educación Infantil es socioconstructivista, basándose en el constructivismo psicogenético de Piaget, el constructivismo social de Vigotsky y el aprendizaje significativo de Ausubel.

\subsection{Metodología: Estudio de casos.}

Teniendo en cuenta los objetivos de la investigación, el contexto de la misma y otros aspectos influyentes, se optó por la estrategia metodológica del estudio de casos, debido a considerarla como la más adecuada para realizar esta investigación cualitativa los motivos específicos detallados a continuación:

- Se trata de investigar acerca del comportamiento humano de los/las docentes y su repercusión en el alumnado.

- Es una muestra reducida.

- Existen múltiples variables que no pueden ser controladas [emociones, metodología de trabajo dinámica, respuestas del alumnado].

Estudiamos cómo trabajan los docentes de la etapa de Educación Infantil, focalizamos nuestro seguimiento en tres de ellos. El motivo de optar por esta muestra se basa en que actualmente cada uno es tutor de su aula y tienen en común que pertenecen al Grup Xucurruc, siendo esta escuela la única de la Vall d'Albaida que tiene el 75\% del profesorado de Educación Infantil en dicho grupo. Prestaremos atención a la metodología que se utiliza, qué priorizan en ella y de qué parten para que el alumnado aprenda. 


\subsection{Fuentes de recogida de datos.}

Esta investigación se basa en un estudio ex post facto, de manera descriptiva y utilizando para ello las siguientes fuentes de recogida de información:

- Registro de las entrevistas en formato audio y transcripción de las mismas.

- Notas de campo de lo que ocurrió antes, durante y después de las entrevistas.

- Observación directa en las aulas.

- Material bibliográfico [en formato de papel, digital y también vídeos].

El eje central de esta investigación son las entrevistas y se ha querido enriquecer con las diferentes fuentes de recogida de datos, de manera que pueda conseguirse una mayor precisión y detalle en la misma. El motivo de incluir notas de campo de lo acontecido en las entrevistas es para mejorar este estudio y respaldarlo con otros datos, puesto que aportaban información de lo que iba aconteciendo de manera espontánea y también de aquello a lo que los docentes daban importancia. Las notas de campo nos ayudan a recordar cómo acontecieron las cosas debido a las contribuciones que realizan los entrevistados cuando se apaga la grabadora, en la que expresan cómo se han sentido o aportan información de manera más confidencial. No debemos olvidar también que la parte subjetiva, la emoción, las experiencias y sentimientos estarán presentes en aquellos que se estudia.

A continuación se describe el perfil de la muestra, su equivalencia en los pseudónimos utilizados para las entrevistas, así como también los motivos por los que se ha seleccionado a cada uno de los entrevistados por su relevancia en el desarrollo de la investigación: P1: Tutor/a de la clase de 4 años de Educación Infantil e integrante del MRP Grup Xucurruc. P2: Tutor/a de la clase de 3 años de Educación Infantil, integrante del MRP Grup Xucurruc y encargado de gestionar y dirigir proyectos musicales del centro. P3: Tutor/a de la clase de 5 años de Educación Infantil, integrante del MRP Grup Xucurruc, miembro de la COCOPE, dinamizadora y motor de esta etapa educativa.

Para acabar este apartado, se remarca que la observación directa y la participación activa en las clases sirvieron para poder entender y vivenciar en primera persona la información que los docentes aportaban en sus entrevistas, ya que, como argumenta Barba [2013]: "la observación participante hace que el observador se integre en determinados procesos del grupo, con lo que hay que hacerlo con cuidado para no contaminar el contexto, pero a la vez los participantes lo perciben con más confianza". 


\subsubsection{Entrevista.}

El tipo de entrevista utilizada para esta investigación es la semiestructurada. Se elaboró un guión de unas 40 preguntas abiertas, agrupadas en varias categorías, permitiendo dinamizar más las entrevistas y posibilitar que surgiera otra información de interés en su transcurso. Las entrevistas se realizaron en valenciano por ser su lengua materna. Se optó por registrarlas con una grabadora de voz digital modelo Olympus VN8600PC, que ha permitido no interferir en la comodidad de los entrevistados. Dado el lugar de realización de éstas, el formato de audio proporcionaba mayor flexibilidad y privacidad. El tiempo destinado a cada entrevista fue flexible y variable.

\subsubsection{Transcripción.}

Para realizar la transcripción de las entrevistas, nos hemos basado en la convención de transcripción de Jefferson y se han ampliado los códigos con otros oportunos para conseguir una mayor riqueza y precisión de datos en las entrevistas.

\section{Análisis y discusión}

Los pasos que hemos seguido para realizar el análisis han sido los siguientes:

1. Obtener la información mediante las fuentes propuestas para ello: Entrevistas a docentes, notas de campo, observación directa en las aulas y material bibliográfico (en formato de papel, digital y también vídeos].

2. Capturar la información, transcribirla y ordenarla. Las entrevistas se grabaron en audio, se transcribieron y posteriormente se numeraron las frases para permitir una mejor localización de la información. Las notas de campo se registraron en papel.

3. Codificación. En este tercer paso se realizó la codificación de la siguiente manera: se utilizaron tres colores correspondiendo cada uno a las respuestas de un entrevistado. Se asignaron unidades de significado a la información recopilada de las entrevistas. Las unidades de significado se organizaron mediante un código que referenciaba a la información que conlleva. Para seguir refinando la información, se procedió a varias relecturas de los códigos identificándolos como temas principales, temas importantes y temas descartables. Estas tres categorías emergentes permitieron que la información quedara más seleccionada. Posteriormente, se procedió a englobar en categorías todas las unidades de significado relevantes para esta investigación. El resultado fueron seis categorías de información con sus correspondientes subcategorías: 


\section{CONDICIONANTES DOCENTES ADMINISTRATIVO}

1.1. Formación de los docentes.

1.2. Centro de trabajo y antecedentes.

\section{TRAYECTORIA FORMATIVA DOCENTE}

2.1. Formación continua: cursos, seminarios, modelos pedagógicos, intereses particulares. 2.2. Interés formativo particular.

\section{ASPECTOS CURRICULARES}

3.1. Presencia curricular de la música y el arte en la Educación Infantil.

3.2. Presencia curricular de la educación emocional.

\section{ASPECTOS METODOLÓGICOS}

4.1. Trayectoria evolutiva de la metodología.

4.2. Implicaciones del cambio metodológico.

\section{CAMBIOS COLATERALES METODOLÓGICOS}

5.1. Factores que intervienen en la metodología.

5.2. Repercusión metodológica.

\section{ALGUNAS INTELIGENCIAS MÚLTIPLES}

6.1. Gestión de la educación emocional.

6.2. Arte y música: interniveles y la transdisciplinariedad educativa.

\section{Conclusiones}

Podemos señalar como conclusiones más relevantes las siguientes:

En respuesta al objetivo general que trata de observar la metodología de trabajo de las artes y comprobar la relevancia que tienen la creatividad y la inteligencia emocional, se subrayan varios aspectos:

a) Un factor relevante como es la importancia del entorno emocional, lo destaca Odena [2013, p. 108] al comentar que: "un entorno emocionalmente estable se considera como facilitador de los lazos emocionales con los materiales sonoros, la motivación y el progreso de todos los estudiantes". Para trabajar este entorno, se requiere de un compromiso grupal docente que transcienda hasta el alumnado, de manera que éste se forme en la alfabetización emocional, aprovechando las herramientas que proporcionen los docentes y puedan iniciarse en autorregular las emociones. 
b) Otro factor que se destaca es el agrupamiento de interniveles para trabajar artes y música. Así el aprendizaje se realiza entre iguales y se fomentan valores como la tolerancia, el respeto y el compañerismo entre otros, puesto que el trabajo tiene un objetivo que se alcanza a nivel grupal, no individual.

c] El último factor que se recalca dentro del objetivo general es la formación que poseen los docentes y que les permite seguir evolucionando en su práctica hacia una mejor forma de realizar su trabajo. Se ha de entender el comportamiento del alumnado de Educación Infantil y saber qué proceso madurativo desarrolla en cada etapa, no sólo se ha de atender a los estadios socievolutivos establecidos por Piaget, sino ir un paso más allá. Aquí es donde radica la importancia de tener conocimientos sobre el hemisferio derecho del cerebro y lo que éste comporta. En este aspecto, se puede identificar actualmente para los docentes cierta escasez formativa por parte de la administración. Por este motivo se adhieren los docentes al Grup Xucurruc que les permite un crecimiento profesional que palia las carencias de la formación ofertada y dan respuesta a su curiosidad. Esta formación proporcionaría una visión más amplia para los profesionales de la educación que permitiría entender mejor el comportamiento del alumnado y colaboraría a la eliminación de ciertas "etiquetas" hacia el alumnado.

Si el docente no recibe formación en este campo, será complicado que pueda entender el comportamiento del alumnado en ciertos momentos y le será más complejo no establecer adjetivos como por ejemplo "malo" a un alumno que utilice la violencia cuando se siente intimidado por otro. Aquí es donde emerge la importancia de la autorregulación del alumnado porque otorga un equilibrio entre el córtex prefrontal y la amígdala. Goleman [2012, p .38) explica que:

La autorregulación de las emociones y los impulsos depende en gran medida de la interacción entre el córtex prefrontal [el centro ejecutivo del cerebro] y los centros emocionales del cerebro medio, en particular los circuitos que convergen en la amígdala.

La amígdala cerebral es la responsable de generar sentimientos de angustia, ira, rabia, impulsos etc. De ahí la importancia que el personal docente pueda contar con este tipo de formación.

Aludiendo al primer objetivo secundario en el que pretendíamos comprobar si es la metodología el factor más relevante en la formación del alumnado, se detectan varios aspectos más importantes que la metodología utilizada en el centro educativo. Se trata de la actitud del docente, sus creencias y aquello que puede transmitir al alumnado. De manera que los contenidos que se impartan en Educación Infantil y la relevancia que cobren unas áreas frente a otras, dependerán de aquello que el docente sea capaz de transmitir al alumnado. Se reconoce con esta justificación que el docente es el motor, el recurso educativo por excelencia y aquello que genere en él unas emociones positivas, será lo que consiga transmitir al alumnado. Durkheim [citado en Acosta, 2011, p. 7] avala esta conclusión argumentando que: 
El arte de la educación no es la pedagogía, sino la habilidad del educador, la experiencia práctica del maestro [...] Si la pedagogía excede los límites de su propio dominio, si pretende substituir a la experiencia y dictar recetas ya listas, para que el practicante las aplique mecánicamente, entonces degenera en construcciones arbitrarias. Pero, por otra parte, si la experiencia prescinde de toda reflexión pedagógica, degenera a su vez en ciega rutina o se pone a remolque de una reflexión mal informada y sin método. Pues, en definitiva, la pedagogía no es otra cosa que la reflexión más metódica y mejor documentada posible, puesta al servicio de la práctica de enseñanza.

La parte emocional es la forma de evaluar y mejorar la práctica docente y por este motivo, se trabajan las emociones continuamente, como argumenta Marina [2011, p. 149]:

Las emociones son modos de evaluar las experiencias, de establecer jerarquías de valores, de cambiar las metas, de disponer para la acción. [...] Recordamos lo que tiene mayor carga emocional porque todos los acontecimientos emocionales reciben un tratamiento preferente.

El siguiente objetivo secundario resta en conocer la importancia que se le otorga a la música y al arte en Educación Infantil en este centro. Por su estrecha relación con las emociones, las artes y la música son consideradas relevantes porque mejoran las relaciones entre iguales, la formación integral del alumnado; les ayudan a expresar sus sentimientos y a fomentar su creatividad. Si les permitimos trabajar de una manera autónoma y les otorgamos voz en su educación, conseguiremos que germine lo mejor del alumnado. Como indica Eisner [2004, p. 43]:

El objetivo de la frase 'la capacidad del niño para desarrollar la mente' es volver a destacar que la educación es un proceso en el que aprendemos a ser los arquitectos de nuestra propia experiencia y, en consecuencia, a crearnos a nosotros mismos. Las artes tienen unas contribuciones muy claras que hacer a este objetivo mediante si énfasis en la expresión de la individualidad y mediante el ejercicio y el desarrollo de la capacidad de imaginación.

Tenemos que tener en consideración la ventaja que esto aporta, es decir, se consigue que el alumnado se exprese de manera individual, atendiendo a las capacidades personales de cada alumno/a y la metodología comentada permite que esa individualidad consiga un fin común, plasmado con un producto final fruto de la cooperación de todo el alumnado. Bien sea al trabajar la música o las artes visuales.

Retomamos de nuevo la educación emocional y con ello, daremos respuesta al siguiente objetivo secundario de identificar la repercusión de las emociones en el aprendizaje. Se demuestra el impacto que tienen al trascender más allá del aula, traspasando a otro elemento de la comunidad educativa como son las familias. Nombraremos las aportaciones que las emociones positivas generan en el ambiente, como expone Ruiz [2010, p. 149]: 
Podríamos afirmar que: en un aula en el que las emociones positivas formen parte del ambiente, el fluir de esa energía creativa será más cómodo y fácil. Pero las emociones además de estar presentes en la persona creativa también lo están en el producto creativo y en el propio ambiente creativo. Todo esto hace que tengamos en cuenta las emociones que en el aula se vivencian si realmente queremos hacer que la creatividad fluya entre sus paredes, es necesario co-construir un ambiente emocional positivo; de ahí la importancia de la educación de las propias emociones.

Las emociones positivas promueven un ambiente de confianza que permite a cada criatura mostrar sus capacidades en su máximo nivel. Por tanto, el generar dicho ambiente será otro factor a tener en cuenta para que la labor docente obtenga mejores rendimientos. Se ha de recordar, que las emociones consideradas como negativas estarán siempre presentes, pero mediante herramientas de autorregulación emocional, el alumnado consigue solucionarlas para sentirse bien de nuevo. La importancia de la autorregulación está en que cuando existe algún tipo de preocupación en el alumnado, éste no puede aprender porque focaliza toda su atención en aquello que le inquieta. En el momento en que logra solucionar el motivo de su malestar, aprende.

Tenemos que tener presente que trabajando mediante experiencias de aprendizaje, éstas dan lugar a las emociones, y las emociones a las creaciones. Según De la Herrán [2000, p. 3]:

\footnotetext{
La creatividad es una experiencia profundamente imbricada en el propio acto de aprender, porque tiene su asiento en la capacidad de descubrir, o sea, de hallar; manifestar; hacer patente o formalizar ideas o experiencias relativamente novedosas u originales. La creatividad tiene que ver con el trazado de nuevas rutas neurológicas, entendidas como desarrollo y expresión de procesos y acciones asociados al encuentro personal y al asombro relativos.
}

$\mathrm{Si}$ a este hecho añadimos lo comentado por Bisquerra en el punto de fundamentación, en el cual explica que las rutas neuronales que tienden a repetirse son las que han producido una experiencia placentera, obtenemos la respuesta a cómo fomentar la creatividad: mediante las emociones y partiendo de los lenguajes que permiten más creaciones en la etapa de Educación Infantil, como son las artes visuales y la música. Se cumple en esta justificación el penúltimo objetivo establecido en el cuál se detecta el contribuir de la música y el arte en las emociones y creatividad del alumnado.

Como respuesta al último objetivo secundario de la investigación, identificamos las siguientes ventajas e inconvenientes de trabajar las artes y la música.

Ventajas:

- El mismo efecto que generan en el alumnado las artes visuales y la música, se plasma también en cada docente, de manera que fortalecen la relación entre ellos. 
- Facilitan y propician el trabajo grupal del alumnado.

- Se consigue un ritmo de aprendizaje que atiende al ritmo de cada alumno/a.

- Es un aprendizaje continuo entre docentes y alumnado que tiene un efecto motivador. También se consigue profundizar en la personalidad de todos/as, incluyendo los docentes.

- Las emociones y el bienestar que generan en el alumnado son transmitidas a las familias, influyendo en la mejora de la relación entre éstas y el centro educativo.

Inconvenientes:

- A nivel docente se ha de tener una actitud positiva hacia estos lenguajes, de no ser así, no lograrán transmitir al alumnado interés por ellos.

- Se requiere formación pedagógica para entender por qué se ha de trabajar de este modo y obtener los beneficios deseados.

Remitiendo las conclusiones de este artículo al Decreto 38/2008, volvemos a incidir sobre la frase siguiente: "El cuerpo es la principal herramienta de relación del sujeto con el mundo que le rodea" [p. 55025], y por tanto la primera fuente de experimentación, comunicación y aprendizaje. El hecho de optar porque el alumnado permanezca pasivo en las aulas, que su formación se centre en fichas y apenas se destine un tiempo para trabajar la parte emocional en las aulas, hace que nos replanteemos algunos aspectos que en pleno siglo XXI parece que todavía no son tenidos en cuenta.

¿Hasta qué grado es educación aquella que en cierto modo queda establecida fuera de la naturaleza del niño? Si el cuerpo es la principal herramienta de relación del sujeto, ¿cómo aprender estando estático? Se ha de mencionar que actualmente, no se invierte a nivel económico en educación y los docentes se ven desbordados en sus clases, tanto por contar con unas aulas excesivamente pobladas, como por poseer cada vez menos recursos formativos. ¿Hasta dónde llega la coherencia del currículum con la política educativa que se establece?

Después de realizar este estudio, concluimos con la necesidad de tener en cuenta las emociones por todo lo que ellas son capaces de aportar y desencadenar. Nuestra vida está repleta de vivencias personales que emanan diferentes tipos de emociones y que influyen en la personalidad que desarrollamos. Vivimos conflictos y contradicciones entre lo que deseamos y aquello que se debe hacer. Algunas veces esos conflictos pueden deberse a cierto "analfabetismo emocional" que según Obiols [2005, p. 149] "es manifesta de múltiples formes: conflictes, violència, ansietat, estrès, depressió, etc. Això es dóna al llarg de tota la vida, però té una virulència particular durant l'edat escolar". Por este mismo motivo, las artes visuales y la música son necesarias para 
proporcionar un desarrollo integral del alumnado y, de manera transdisciplinar permiten trabajar todo tipo de conocimientos y sentimientos que pueden alfabetizar en todos los ámbitos posibles.

\section{Referencias bibliográficas}

-Acosta, M. [2011). Educar, Enseñar, Escolarizar: el problema de la especificación en el devenir de la Pedagogía [y la transmisión]. Trabajo presentado en el VIII Encuentro de Cátedras de Pedagogía de Universidades Nacionales Argentinas, Agosto, La Plata. Recuperado de: http:/ / ecpuna.fahce. unlp.edu.ar/actas/Acosta-_Felicitas_Maria.pdf

-Amagi, I., Al Mufti, I., Carneio, R., Chung, F., Delors, J., Geremek, B., Gorham, W., Kornhauser, A., Manley, M., Padrón, M., Savané, M.A., Singh, K., Stavenhagen, R., Nanzhao, Z. \& Won, M. [1996]. La educación encierra un tesoro. Informe a la UNESCO de la Comisión Internacional sobre la Educación para el siglo XXI. Ediciones Unesco, 34. Recuperado de: http:/ / unesdoc.unesco.org/ images/0010/001095/109590so.pdf

-Arnheim, R. [1993].Consideraciones sobre la educación artística. Barcelona: Paidós.

-Barba, J. J. [2013]. La investigación cualitativa en educación en los comienzos del siglo XXI. En M. Díaz y A. Giráldez. [Coords.], Investigación cualitativa en educación musical [pp.23-38]. Barcelona: Graó.

-Bisquerra, R. [2013]. Educación emocional. Propuestas para educadores y familias. Bilbao: DESCLÉE.

-Csikszentmihalyi, M. [1998]. Creatividad. El fluir y la psicología del descubrimiento y la invención. Barcelona: Paidós.

-Decreto 38/2008 del 28 de marzo del 2008 por el que se establece el currículum del segundo ciclo de la Educación Infantil de la Comunidad Valenciana. Recuperado de: http:/ / www.dogv.gva. es/datos/2008/04/03/pdf/2008_3838.pdf

-De la Herrán, A. [2000]. Hacia una creatividad total. Arte, individuo y sociedad, 12 [1], 71-89. Recuperado de: http://revistas.ucm.es/index.php/ARIS/article/viewFile/ ARIS0000110071A/5921

-De la Torre, S. [2006]. Creatividad cuántica una mirada transdisciplinar. Recuperado de: http:/ / www.encuentros-multidisciplinares.org/Revistan\%BA28/Saturnino\%20de\%20la\%20 Torre\%20de\%20la\%20Torre.pdf

-Eisner, E. [2004]. El arte y la creación de la mente. El papel de las artes en la transformación de la consciencia. Barcelona: Paidós. 
-Eisner, E. [2004]. El arte y la creación de la mente. El papel de las artes en la transformación de la consciencia. Barcelona: Paidós.

-Eisner, E. [2005]. Educar la visión Artística. Barcelona: Paidós.

-Gardner, H. [1994]. Estructuras de la mente. La teoría de las inteligencias múltiples. México: Fondo de Cultura Económica.

-Gardner, H. [2004]. Educación artística y desarrollo humano. Barcelona: Paidós.

-Goleman, D. [1996]. Inteligencia Emocional. Barcelona: Kairós.

-Goleman, D. [2012]. El cerebro y la inteligencia emocional: Nuevos descubrimientos. Barcelona: Ediciones B.

-Marina, J. A. [2011]. El cerebro infantil: la gran oportunidad. Barcelona: Ariel.

-Obiols, M. [2005). Disseny, desenvolupament i avaluaciód'un programa d'educació emocional en un centre educatiu. Tesis Doctoral. Universitat de Barcelona. En: http://www.tdx.cat/ handle/10803/2347

-Odena, 0. [2013].Creatividad en educación musical: una exploración cualitativa. En M. Díaz, M. y A. Giráldez. [Coords.], Investigación cualitativa en educación musical. (pp. 99-115]. Barcelona: Graó.

-Ruiz, S. [2010]. Práctica educativa y creatividad en educación infantil. Tesis Doctoral. Universidad de Málaga. En: http://riuma.uma.es/xmlui/bitstream/handle/10630/4618/TDR_RUIZ_ GUTIERREZ.pdf?sequence=6

-Swanwick, K. [2000]. Música, pensamiento y educación. Madrid: Morata.

-Technology, Entertainment, Design. [Productor]. [2006). Las escuelas matan la creatividad. En: http:/ /www.grao.com/articles-tc/nuevas-miradas/creatividad-ken-robinson

-Toro, J. M. [2008]. La creatividad del "co-razón". Creatividad y sociedad 12,1-20. Recuperado de: http://www.creatividadysociedad.com/articulos/12/Creatividad\%20y\%20Sociedad.\%20 La\%20creatividad\%20del\%20corazon.pdf 